\title{
A threshold loading device for testing of inspiratory muscle performance
}

\author{
P.R. Eastwood*+, D.R. Hillman*
}

A threshold loading device for testing of inspiratory muscle performance. P.R. Eastwood, D.R. Hillman. @ CERS Journals Ltd 1995.

ABSTRACT: Threshold loading is a method of incrementally loading the inspiratory muscles, which requires development of an adjustable threshold pressure (Pth) before air will flow. In the ideal device, flow is independent of pressure once Pth is exceeded. A "weighted plunger" apparatus is commonly used, but devices described previously perform unreliably at high inspiratory load.

We have modified this apparatus using the diaphragm and valve seating from a threshold valve used to deliver positive airway pressure (AMBU 10, AMBU International, Denmark) to yield improved pressure-flow characteristics.

With this device, there was a linear relationship between $P_{t h}$ and weight on the plunger $(r=0.998)$, and flow was largely independent of pressure once $P$ th was exceeded: pressure developed at an inspiratory flow of $1.3 \pm 0.1 l \cdot \mathrm{s}^{-1}$ was $13.6 \pm 7.0 \%$ below Pth.

Our modified weighted plunger apparatus allows consistent and reliable threshold loading of inspiratory muscles, even at high inspiratory loads.

Eur Respir J., 1995, 8, 463-466.
*Dept of Pulmonary Physiology, Sir Charles Gairdner Hospital, Nedlands, Western Australia. +Dept of Human Movement, University of Western Australia, Nedlands, Western Australia.

Correspondence: D.R. Hillman

Dept of Pulmonary Physiology

Sir Charles Gairdner Hospital

Verdun Street

Nedlands

Western Australia

Australia 6009

Keywords: Loaded breathing respiratory muscles weighted plunger

Received: June 281994

Accepted after revision December 281994
Respiratory disease can abnormally load the respiratory muscles. Understanding of the mechanisms by which these muscles cope with increased loads has been greatly enhanced by numerous studies which have simulated internal loads using external mechanical loading. A common method of externally loading the respiratory system is "threshold" loading, which requires a given threshold pressure $(\mathrm{Pth})$ to be developed before air will flow. In the ideal device, once $P$ th is exceeded flow increases independently of pressure. As respiratory muscles act to generate pressures, the method is appropriate to their study, particularly as load is relatively independent of flow and volume change and so cannot be manipulated by change in respiratory pattern, and also because the necessity to breathe provides the incentive to continue to generate Pth.

A popular principle for threshold loading of inspiratory muscles is the weighted plunger apparatus, first described by Nickerson and KeEns [1]. Studies using devices based on the plunger principle include investigation of muscle responses to load [2-4], how they fatigue $[2,5,6]$, the effects of training $[7,8]$, and the consequences of disease [9-11].

However, whilst these devices appear to perform adequately at lower loads, at higher loads there is a less consistent relationship between weight on the plunger, Pth, and resistance to flow beyond Pth $[1,12]$. In this paper, we describe a modification of the NICKERSON and KEENS device [1], which provides relatively precise control of the $\mathrm{P}$ th regardless of its magnitude or of inspiratory flow.

\section{Methods}

We constructed two threshold loading devices, one based on the original design of NICKERSON and KEENS [1], and a modified device with improved performance characteristics.

\section{Apparatus}

Original threshold loading device. A weighted inspiratory plunger was constructed (fig. 1). The device consisted of a two-way Hans-Rudolf valve connected to a chamber. The rubber diaphragms of the Hans-Rudolf valve were made slightly more rigid, so as to resist distortion and maintain a seal during the generation of high inspiratory pressures. At the base of the chamber was a weighted plunger which rested on a rubber "O" ring and was mounted over a large opening [1]. The plunger extended outside the inspiratory chamber [7], and guides inside the chamber ensured vertical displacement of the plunger, since the pressure load produced by the valve is highly dependent on its vertical orientation [4]. Inspiratory flow was measured with a pneumotachograph (Fleisch No. 2) which was connected between the inspiratory side of the Hans-Rudolf valve and the inspiratory plunger. Inspiratory pressure was measured at the mouthpiece with a differential pressure transducer (model PM131, Statham Instruments, Oxnard, Ca, USA). 


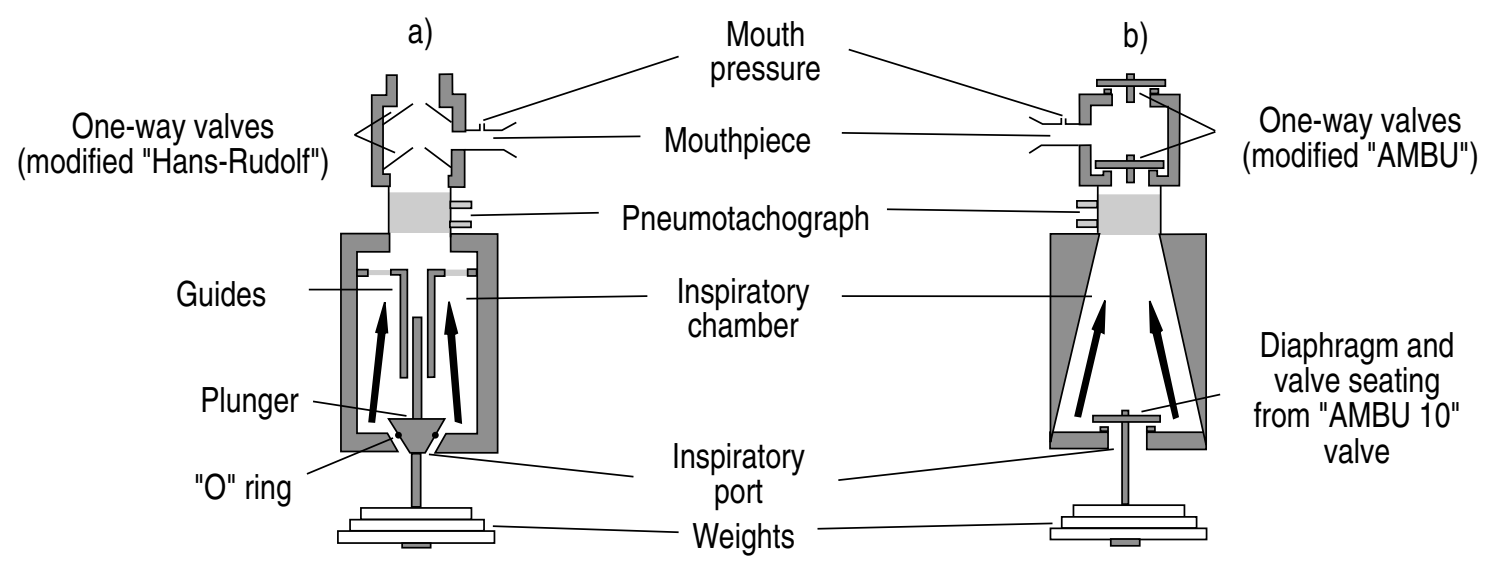

Fig. 1. - Schematic diagram of: a) the original threshold device; and b) the modified threshold device, used to provide an inspiratory threshold load to subjects breathing on the mouthpiece. The inspiratory plunger of the original device was replaced using the diaphragm and valve seating from an AMBU PEEP valve (see text), as were the two one-way valves. PEEP: positive end-expiratory pressure.

Modified threshold loading device. The major modification of this original device was the substitution of the "O" ring and plunger with the diaphragm and valve seating from a threshold valve used to deliver positive endexpiratory pressure (PEEP) (AMBU 10, AMBU International, Denmark). The valve seating (internal diameter $=2.38 \mathrm{~cm}$ ) was positioned in the base of the chamber (fig. 1b). The central spindle running through the valve diaphragm was lengthened a further $10.5 \mathrm{~cm}$ to form a plunger, to permit addition of weights to the valve as with the original device. A vertical guide was unnecessary, because the mechanical linkage of the central spindle of the AMBU PEEP valve to its diaphragm, which incorporates fluid damping, allows for lateral motion of the central spindle independent of the valve diaphragm. This coupling allowed the valve seal to be maintained even with significant lateral movement of the plunger, in contrast to the original device.

Distortion and leakage of the diaphragms of the HansRudolf valve during the generation of highly negative inspiratory pressures (often in excess of $200 \mathrm{cmH}_{2} \mathrm{O}$ ) was an intermittent problem. This was overcome by replacing them with the diaphragms and valve seatings from another two AMBU PEEP valves to form the two-way valve system.

In addition, the interior of the inspiratory chamber was tapered $(9.2 \mathrm{~cm}$ high $\times 5.2 \mathrm{~cm}$ (internal diameter of base) $\times 3.0 \mathrm{~cm}$ (internal diameter of top)) to encourage laminar airflow and improve the accuracy of measurements of inspiratory flow with the pneumotachograph (fig. 1b). Inspiratory flow and pressure were measured as described above.

\section{Procedure}

The pressure-flow characteristics of each device were obtained by attaching a vacuum pump, with which flow could be varied to the mouthpiece of the valve, and measuring pressure at the mouthpiece with activation of the pump. Pth, the pressure developed at the onset of inspi- ratory flow, was recorded, as was the relationship between pressure and flow beyond this threshold. One hundred gram weights were added to the inspiratory plunger, to a maximum of $1,200 \mathrm{~g}$, to produce varying Pth. Once Pth was achieved, flow was gradually increased and then maintained constant (for $>5 \mathrm{~s}$ ), at each of 5-8 increments ranging $0.2 \pm 0.1-1.3 \pm 0.1 l \cdot \mathrm{s}^{-1}$. The pressure at each increment of flow was recorded, and the relationships between pressure and flow for each device at each weight were examined (figs 2 and 3 ).

\section{Statistics}

Linear regression analysis using the least-squares method was used to examine the relationship between $P$ th and weight on the plunger. All data are expressed as mean \pm SD.

\section{Results}

The design of the inspiratory valve is the primary determinant of the performance characteristics of threshold loading devices. The original device appeared to operate reasonably satisfactorily at low weights and inspiratory pressures. However, at higher inspiratory pressures the independence of inspiratory flow from pressure above Pth was lost with resultant variability in pressure over the range of flows examined (fig. 2). The modified device demonstrated markedly improved pressure-flow characteristics, with a linear relationship between Pth and weight on the plunger $(r=0.998 ; p<0.001)$, and flow largely independent of pressure once Pth was exceeded: pressure developed at an inspiratory flow of $1.3 \pm 0.1 \quad l \cdot \mathrm{s}^{-1}$ was $13.6 \pm 7.0 \%$ below Pth (fig. 3). The size of the valve diaphragm determines the relationship between plunger weight and Pth: the larger diaphragm of the AMBU valve resulted in a less negative Pth for a given weight in the modified device than in the original. 


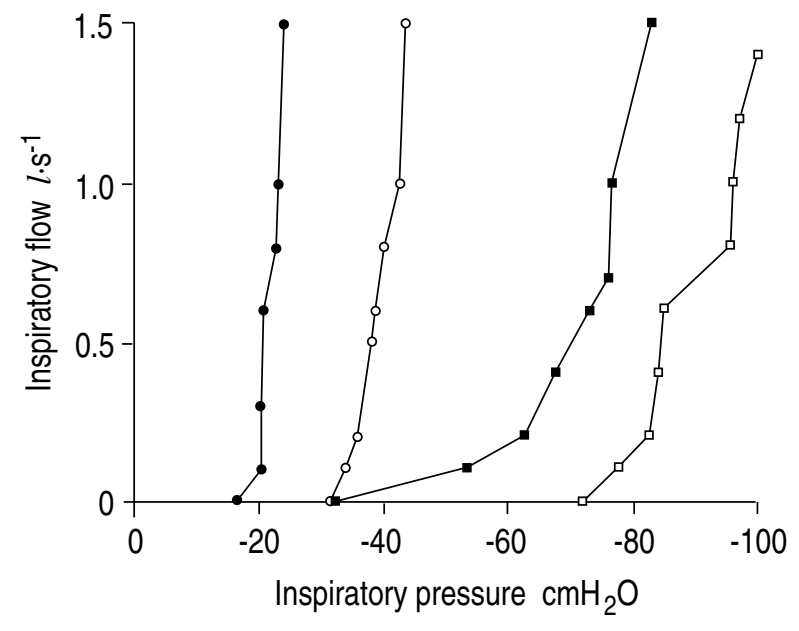

Fig. 2. - Pressure-flow characteristics of the original threshold device, with various weights added to the inspiratory plunger. Performance characteristics are similar to the device designed by NICKERSON and

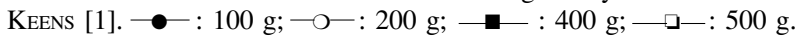

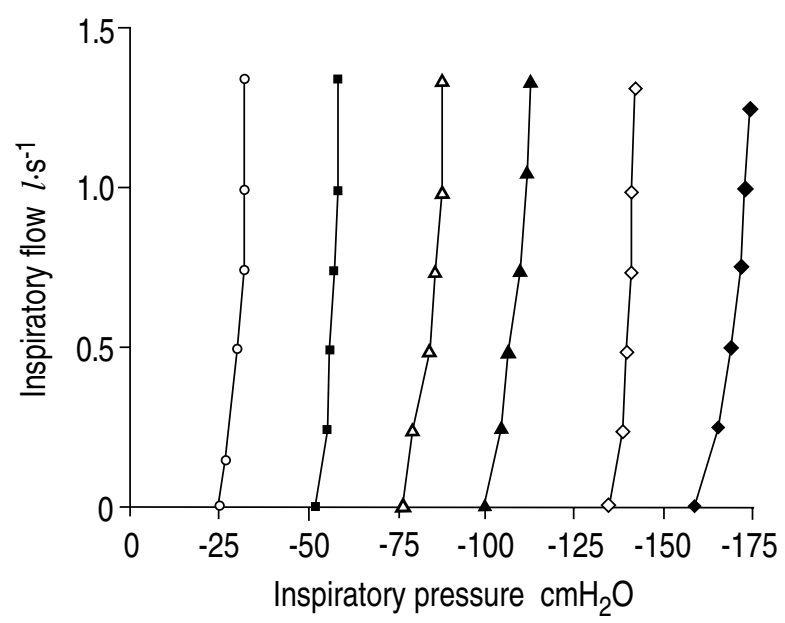

Fig. 3. - Pressure-flow characteristics of the modified device, with various weights added to the inspiratory plunger. Note the improved performance characteristics. $\multimap-: 200 \mathrm{~g} ;-\square: 400 \mathrm{~g} ; \multimap-600$ $\mathrm{g} ; \multimap$ \ $: 800 \mathrm{~g} ; \multimap \checkmark: 1,000 \mathrm{~g} ; \multimap: 1,200 \mathrm{~g}$.

\section{Discussion}

The unreliable performance at high loads of the original device has been observed by others [12]. Indeed, the original description of the device demonstrates an interdependence of pressure and flow at low flows, particularly with heavy weights on the plunger [1]. Perhaps in recognition of the problem, NICKERSON and KEENS [1] defined Pth as the pressure developed at "significant" inspiratory flow $\left(>0.05 l \cdot \mathrm{s}^{-1}\right)$, rather than the pressure developed at the onset of inspiratory flow (see Methods). Although they reported a close correlation between the weight on the plunger and Pth $(r=0.99 ; \mathrm{p}<0.0001)$ [1], it is likely to have been less impressive if our more rigorous definition of Pth had been used: their device demonstrated significant leakage through the valve at pressures below the pressure they used to define Pth. The prob- lems of the original device at low flows appear to relate to partial lifting of the plunger from its seating on the "O" ring (fig. 1a), with inspiratory flow occurring at variable inspiratory pressures. This rocking of the valve on the "O" ring is difficult to prevent, even with careful vertical alignment of the plunger [4]. If the guides of the original device, which maintain vertical orientation of the plunger, are fitted too close then significant friction occurs between them and the plunger, again adversely affecting performance of the valve. The modified device obviates the need for guides (see Methods).

Recently, BARDSLEY et al. [12] designed a solenoid valve in an attempt to overcome these problems. In this device, once Pth was exceeded the solenoid valve opened. However, the device imposed a threshold load only during initial inspiratory effort, with load disappearing for the remainder of inspiration [13]. In contrast, the weighted inspiratory plunger imposes a threshold load throughout inspiration: if $\mathrm{Pth}$ is not exceeded, no inspiratory flow can occur. A modified servo-controlled valve, designed to maintain Pth constant throughout inspiration would be ideal, although a more complex and expensive solution than that which we have proposed.

We have used our modified device to study breathing pattern under load, and aspects of inspiratory muscle fatigue and endurance [2]. In this study, seven subjects were studied on $17 \pm 6$ separate occasions ( $\geq 24 \mathrm{~h}$ apart) during progressive threshold loading [8]. During this series of measurements the relationship between pressure measured at the mouth and the weight on the plunger remained linear, so that inspiratory load could be accurately incremented. The finding that, after a learning period, maximum $P$ th achieved by each subject was reproducible with a coefficient of variation of $5 \pm 2 \%$ [2], suggests that the device behaves reproducibly in vivo. We believe that our modified valve provides a simple but effective way to predictably and reliably threshold load the inspiratory muscles.

\section{References}

1. Nickerson BG and Keens TG. Measuring ventilatory muscle endurance in humans as sustainable inspiratory pressure. J Appl Physiol: Respirat Environ Exercise Physiol 1982; 52(3): 768-772.

2. Eastwood PR, Hillman DR, Finucane KE. Ventilatory responses to inspiratory threshold loading and role of muscle fatigue in task failure. J Appl Physiol 1994; 76(1): 185-195.

3. Morrison NJ, Fairbarn MS, Pardy RL. The effect of breathing frequency on inspiratory muscle endurance during incremental threshold loading. Chest 1989; 96(1): 85-88.

4. Clanton TL, Dixon GF, Drake J, Gadek JE. Effects of breathing pattern on inspiratory muscle endurance in humans. J Appl Physiol 1985; 59(6): 1834-1841.

5. Mador MJ, Acevedo FA. Effect of respiratory muscle fatigue on breathing pattern during incremental exercise. Am Rev Respir Dis 1991; 143: 462-468.

6. Supinski GS, Clary SJ, Bark H, Kelsen SG. Effect of inspiratory muscle fatigue on perception of effort during loaded breathing. J Appl Physiol 1987; 62(1): 300-307. 
7. Clanton TL, Dixon G, Drake J, Gadek JE. Inspiratory muscle conditioning using a threshold loading device. Chest 1985; 87(1): 62-66.

8. Martyn JB, Moreno RH, Pare PD, Pardy RL. Measurement of inspiratory muscle performance with incremental threshold loading. Am Rev Respir Dis 1987; 135: 919-923.

9. Hopp LJ, Kim MJ, Larson JL, Dan A, Patel M, Sharp JT. Incremental threshold loading in chronic obstructive pulmonary disease (COPD) patients. Am Rev Respir Dis 1993; 147(4) (Suppl.): A695.

10. Wanke T, Formanek D, Lahrmann H, Merkle M, Rauscher $\mathrm{H}$, Zwick H. Inspiratory muscle performance relative to the anaerobic threshold in patients with COPD. Eur. Respir J 1993; 6: 1186-1191.

11. Kelsen SG, Rao L, Cherniack NS, Gothe B, Altose MD. Respiratory adjustments to ventilatory loading in chronic obstructive pulmonary disease. Am Rev Respir Dis 1979; 119(2) (Suppl.) Part 2: 159-164.

12. Bardsley PA, Bentley S, Hall HS, Singh SJ, Evans DH, Morgan MDL. Measurement of inspiratory muscle performance with incremental threshold loading: a comparison of two techniques. Thorax 1993; 48: 354-359.

13. Eastwood PR, Hillman DR. Solenoid valve $v s$ weighted plunger in incremental inspiratory threshold loading, (Letter to the Editor). Thorax 1994; 49: 94. 